\title{
Evaluative Component of the Artistic Discourse and Its Means of Actualization in the Short Stories by W.S. Maugham \\ Ekaterina Vladimirovna Smyslova
}

\author{
Lecturer in English, Kazan Federal University, \\ Kremliovskaya str, 18, 420008, Kazan, Russian Federation
}

\section{Guzel Rinatovna Eremeeva}

Associate Professor, Kazan Federal University, Kremliovskaya str, 18, 420008, Kazan, Russian Federation

Doi: 10.36941/ajis-2019-0035

\section{Abstract}

The article focuses on the means of realization of the evaluative component of the syntactic evaluative constructions at the text level. The analysis of the two short stories by W.S. Maugham shows that there are two ways of evaluative component actualization in the discourse. The first level is represented by direct and indirect appraisals towards the characters and the events of the story given by the author explicitly (through the narrator's speech) or implicitly (through the author's indirect evaluations) while the second one is the interaction of the two narrative methods made by the author and the narrator which leads to the unification of the two defined parties and the following integration of its evaluative component into the title itself.

Keywords: Linguistics, English Language, Evaluative Construction, Artistic Discourse, Subjective Narration

\section{Introduction}

Nowadays the study of evaluative components at the text level is of great interest in the modern linguistics development as the problem of correlation and interaction of semantics and pragmatics has assumed importance. Taking into consideration E. M. Volf's concept, it is believed that the semantic and pragmatic aspects are inseparable in the evaluation, since all the components of its functioning (subject, object, evaluation aspect, evaluation stereotype and evaluation scale) reflect the fusion of semantics (the meanings of language units themselves, including the statement as a whole) and pragmatics (conditions for the implementation of the communication process) (Volf 1985). It is worthwhile noticing that in the paper the discourse is considered to be the whole text, thus it supports the standpoint of another significant Russian linguist, M. Y. Bloch (Bloch 2000). Moreover, it seems quite obvious to note that, in fact, the reality of the text is evaluative in its essence as it is a reflection of the author's vision of the world that is the text is already subjective.

\section{Methods}

While preparing the article such methods as study research, analysis, synthesis, studying and generalization of linguistic research were used. In addition, the paper uses the analysis of the fictional world created in the novels as a means of its consideration. 


\section{Results}

The assessment is often not independent in the text. It is included as a part of description or reasoning with its argumentation and is organically linked to the descriptive side of the text as a whole (Volf 1985: 204). People do not carry out evaluations according to their attitude towards the world. They assess things in accord with the conceptual world of the participants in the communication process, where the assessment puts the object in a certain area of the evaluation scale. In other words, evaluation puts objects in their places in the world picture of values, determining their relationship. In texts, the assessment can be expressed by combining linguistic means with introducing fragments of the values world picture. As a result, the assessment can be regarded as a separate aspect of language expressions, which is superimposed on the descriptive content, where the description reflects the picture of the world as such. Meanwhile, the assessment focuses on its value side, which is determined by the interaction of the world and man with his value orientations. As it has already been noted, evaluation is always present in all types of texts, even if it is implicit. However, linguistic analysis is of interest primarily to those texts where the evaluation is expressed explicitly.

\section{Discussion}

The text which is under consideration is a short story by W. S. Maugham entitled "The Alien Corn". It contains an openly expressed assessment and represents a subjective narrative. According to $\mathrm{E}$. A. Goncharova (Goncharova 1984), the subjective narrative is understood as the type of epic text, where the image develops being based on a personal, i.e. subjective opinion, or the narrator's one. The narrator can be either an irrelevant teller or one of the characters of the story. In this type of the text the narrative structure is based on first-person pronouns. Thus, this narrative method is usually referred to as a first-person narrative.

The term "subjective narration" is referred in this article as the first-person narrative is used in the studied texts. It is conveyed in the psychological core of the narrative, presented in the form of the hero-narrator, speech and reflex plane which prevails in the text. It should be noted that the term "subjective narration" is correlated with the frequently used in linguistics concept of subjectivemodal meaning, expressing the attitude of the speaker to the reported (Paducheva 1996). Sharing I. R. Galperin's point of view on the difference between phrasal and textual subjective-evaluative modality, artistic discourse from the first person is understood as a structural basis for the expression of the subjective-evaluative modality of the whole text (Galperin 2009; Jahani et al, 2016).

In modern linguistic studies, subjective modality is considered in a number of grammatical and semantic phenomena belonging to a broader phenomenon of authorization, which is thought to be a complication of the meaning of the statement due to the implementation of the speaker's position (Agadzhanova 1997, Andreeva 1998, Sakaeva, Sabirova, Yahin 2018; Deyhim \& Zeraatkish, 2016). However, it seems necessary to note the duality of the communicative and functional position of the narrator, where he or she takes part in both the depicted reality and its reflection, and is the same object and subject of the narrative. This inherent contradiction of the narrator finds its expression in the technique of narration: the speech of the subject equally contains the characteristics and subjectivity of the statement, with a functionally pragmatic attitude (to see, to portray, to evaluate) and its objectivity (to be the subject of characterological or typological orientation).

In "The Alien Corn" by W.S. Maugham the hero-narrator, whose name remains unknown, tells the reader the story of a Jewish family living in England, thus acting as an objective narrator. This is reflected in the author's use of evaluative constructions that are objective statements when the narrator depicts, for example: English society of that time

(1) "At that period English society was still a closed body and it was not easy for a Jew to force its barriers, but to Ferdy they fell like the walls of Jericho. He was handsome, he was rich, he was a sportsman and he was good company" (Maugham 2006: 34);

(2) "I give it [the story] here because it is a curious little incident concerning persons whose 
names at least will live in the social history of the Victorian Era and I think it would be a pity if it were lost" (Maugham 2006: 36);

(3) "Society was mixed now, parties were rowdy, but Ferdy fitted himself to the new life» (Maugham 2006: 41); city of Munich:

(4) "Munich is a city that frolics demurely and except about the Marienplatz the streets were still and empty» (Maugham 2006: 73); the attitude of the hero of the story, Freddy, for his sons:

(5) "Freddy was severe with him [Harry], and often impatient, but with George he was all indulgence. Harry would go into the business, he had brains and push, but George was the heir. George would be an English gentleman» (Maugham 2006: 47).

However, it should be noted that the objective narrative immediately acquires the subjective character, as soon as the reader encounters first-person plural pronoun we, for example:

(6) "In England we have so much bad weather that it is only fair that a beautiful day should be more beautiful than anywhere in the world and this June evening was perfect" (Maugham 2006: 49).

Despite the fact that this sentence is about English weather, the capricious nature of which is well-known, the first-person plural narrative in this sentence is an artistic form where the narrator's explicitly expressed point of view has priority. It leads to the creation of a common subjective-evaluative modal plane of the narrative. The thing is that the heronarrator is a close friend of the family told about in the story, and he, like no other, is actively involved in solving and assessing the problem that arose in this family.

The peculiarities of the interaction between the author and the narrator, the structuring of the narrative in the story have been discussed in literary studies and stylistics for a long time. E. V. Klyuev states the author's desire to give the reader the opportunity to feel the isolation and completeness of the psychologically motivated hero-narrator in the genre form of the story (Klyuev 2000). According to him, there are two types of the story distinguished in the paper: unidirectional, where the assessment of the author and the narrator coincide, and multidirectional, in which the assessment lies on different planes.

The texts under analysis belong to the unidirectional type of stories. The hero-narrator carries out the identifying reference of his narration in his own direct statements like in the above-mentioned story by $\mathrm{S}$. Maugham. Motivational relations between the first person personal pronoun and the text itself are built not only on the subject-logical basis, but they also include expressive and evaluative information that is a part of the author's intention of the work.

Integration and completeness are among the most important linguistic and stylistic categories that convey the author's modality. The integration structure of the text of the analyzed story helps to form the completeness of this work of art. However, the most universal means of the story integration in the text is the title. In this case, the author's assessment is realized not only through the repetition of the sign, but also through the influence of the title on other parts of the text, which contribute to a more capacious expression of the author's point of view, as well as the disclosure and understanding of the author's meaning (Puspitasari et al., 2019; Varela et al., 2017; Kord et al., 2017).

One of the problems raised in the novel by $\mathrm{S}$. Maugham is national chauvinism. The main characters, namely the Blands, are shy of their Jewish origin and seek to impersonate the British, imitating them in everything: in the decoration of the house

(7) "Of course it's very simple», she [Muriel Bland] said. "Just an English house in the country" (Maugham 2006: 45); in manners, education and even in appearance

(8) "After all, we're absolutely English, no one could be more English than George, in appearance and manner and everything; I mean, he's such a fine sportsman and all that sort of thing..." (Maugham 2006: 50).

The motive of alienation and rejection of the Jewish nation reveals in the story not only in the proposals directly denouncing it, e.g.

(9) "I felt that he and I at bottom were equally alien in that company, I because I was a writer 
and he because he was a Jew, but I envied the ease with which he bore himself" (Maugham 2006: 35) but in the title itself.

It should be noted, however, that entitling his novel "The Alien Corn" the author does not mean a separate English world hostile to the Jewish but the world as such being unfriendly and unwelcoming to mankind as a whole. This author's idea reflection can be found in the image of the main character of the story, i.e. George.

George Bland considers himself to be a stranger twice. At first he becomes aware that he is not doing what he is interested in, but what his parents are so impressed with. Then he realizes that he will never achieve recognition, respect and become a professional pianist. Eventually, the real world's rejection results in the hero's alienation and his subsequent suicide. This is confirmed by the explicit implementation of the author's idea:

(10) "It is strange that men, inhabitants for so short a while of an alien and inhuman world, should go out of their way to cause themselves so much unhappiness» (Maugham 2006: 69) with its further integration into the novel title.

In another work by S. Maugham's "Dream" the subjective-evaluative modal plan of the narrative is realized with the help of evaluative constructions used by the hero-narrator in relation to the protagonist, for example:

While the objective-evaluative plan of the narrative is reflected in the explicit author's thoughts about the human mind and its possible perversion, which manifests itself in the form of certain dreams. According to the plot of this novel, the main character tells the reader the story of his wife's death. For several days she has been dreaming about her own husband killing her, throwing her from the top floor of their big house. The family relationships of the characters are tense due to the wife's excessive jealousy and sarcasm, but the main personage of the story has never come up with the idea about the premediated murder of his wife. However, with each new nightmare of his wife, the protagonist pictures more clearly how it could happen. At the end of the story it is still unknown whether the fall of the hero's wife was an accident, a strange coincidence or a wellplanned murder.

\section{Conclusions}

Thus, the integration of the message of this work and its title takes place at the same level as in the previous story that is the author's explicit idea integrates into the title of the work. At the same time, it seems necessary to note that the title of this story ("Dream") can be treated in two ways ('dream' as a series of thoughts, images, and feelings that you experience when you are asleep and a wish to do, be, or have something) as none of them violates the author's intention and the message of the work.

\section{Acknowledgements}

The work is performed according to the Russian Government Program of Competitive Growth of Kazan Federal University.

\section{References}

Agadzhanova, M. G. (1997). Image of the Author as a Semantic Component of Artistic Discourse. Moscow. Andreeva, K. A. (1998). Grammar and Poetics of the Narrative in Russian and English. Tyumen.

Bloch, M. Y. (2000). The dictum in the level structure of the language. Questions of linguistics, 4, $56-67$.

Deyhim, T., \& Zeraatkish, y. (2016). Investigate the trend of rural development in Gachsaran city with Morris method. UCT Journal of Management and Accounting Studies, 4(1), 23-28.

Galperin, I. R. (2009). Text as Object of Linguistic Research. Moscow, URSS.

Goncharova, E. A. (1984). Ways of Linguistic Expression of Author-Character Categories in the Literary Text. Tomsk, Tomsk University Publishing house.

Jahani, A., Rostami, V., \& Shabanzadeh, M. (2016). The Impact of management duty duration on the Operational Cycle duration of the Companies Listed in Tehran Stock Exchange. UCT Journal of Social Sciences and Humanities Research, 4(1), 15-24. 
Klyuev, E. V. (2000) Theory of Absurdist Literature. Moscow, Publishing house URAO.

Kord, H., Noushiravani, Y., Bahadori, M. D., \& Jahantigh, M. (2017). Review and Analysis of Telework Perspective in the Administrative Systems. Dutch Journal of Finance and Management, 1(2), 44. https://doi.org/10.29333/djfm/5820

Maugham, W. S. (2006) Selected Prose. Moscow, Manager.

Paducheva, E. V. (1996) Semantic Research. Semantics of Time in the Russian Language. Semantics of the narrative. Moscow, School "Languages of Russian culture".

Puspitasari, L., In'am, A., \& Syaifuddin, M. (2019). Analysis of Students' Creative Thinking in Solving Arithmetic Problems. International Electronic Journal of Mathematics Education, 14(1), 49-60. https://doi.org/10.12973/iejme/3962

Sakaeva Liliya, R., Sabirova Diana, R., Yahin Marat, A. (2018). Culture and civilization: functional and methodological aspects. Revista Publicando, 5(16), 435-442.

Varela, M. L. R., Araújo, A. F., Vieira, G. G., Manupati, V. K., \& Manoj, K. (2017). Integrated Framework based on Critical Success Factors for E-Commerce. Journal of Information Systems Engineering \& Management, 2(1), 4. https://doi.org/10.20897/jisem.201704

Volf, E. M. (1985). Functional Semantics of Evaluation. - Moscow, Science. 